\title{
ALGUMAS CONTROVÉRSIAS SOBRE A ORIGEM DA VIDA
}

Dimas A. M. Zaia*

Departamento de Química, Centro de Ciências Exatas, Universidade Estadual de Londrina, CP 6001, 86051-990 Londrina - PR, Brasil

Cássia Thaïs B. V. Zaia

Departamento de Ciências Fisiológicas, Centro de Ciências Biológicas, Universidade Estadual de Londrina, CP 6001, 86051-990 Londrina - PR, Brasil

Recebido em 6/8/07; aceito em 29/2/08; publicado na web em 13/8/08

SOME CONTROVERSIES ON THE ORIGIN OF LIFE. In the present paper some controversies on the origin of life are discussed. Did the first living beings on Earth have an autotrophic or heterotrophic origin? What did come first, genetic code or metabolism? Were cells invented early? What was the role of minerals regarding the origin of life?

Keywords: origins of life; prebiotic chemistry; RNA world.

\section{CONSIDERAÇÕES GERAIS}

Como surgiu a vida em nosso planeta sempre foi uma questão que preocupou filósofos, cientistas e as pessoas em geral. Ao longo do tempo, as abordagens mudaram conforme a ciência evoluiu. A teoria da geração espontânea, isto é, o surgimento de seres vivos totalmente formados a partir da matéria inanimada e/ou em estado de putrefação num tempo curto, pode parecer estranha para nós, porém incentivou diversos pesquisadores a fazerem experimentos e a discutir o assunto. Essa teoria foi somente desacreditada pela comunidade científica depois dos experimentos de Pasteur e Tyndall, no século XIX. No entanto, como esses experimentos derrubaram definitivamente a teoria da geração espontânea e estudos de biologia mostraram a grande complexidade dos seres vivos, gerou-se, na comunidade científica, uma sensação de impotência para estudar o problema da origem da vida. Com o passar dos anos e do desenvolvimento científico, principalmente nos campos da geologia e da astronomia, os cientistas começaram a estudar questões, tais como, idade e composição química da Terra, das estrelas e do Sistema Solar e a propor teorias de como elas surgiram. Estas questões também influenciaram os pesquisadores da área biológica que começaram a questionar como surgiu a vida em nosso planeta. ${ }^{1}$

O bioquímico russo Aleksandr I. Oparin, em 1924, e, posteriormente, em 1928, o geneticista inglês John B. S. Haldane propuseram um esquema para estudar a questão da origem da vida em nosso planeta. A Figura 1 mostra um esquema geral da hipótese de Oparin-Haldane, que é baseada no fato de que por meio de reações químicas entre moléculas simples, tais como $\mathrm{CH}_{4}, \mathrm{CO}, \mathrm{CO}_{2}, \mathrm{H}_{2}$, $\mathrm{H}_{2} \mathrm{~S}, \mathrm{HCN}, \mathrm{NH}_{3}, \mathrm{H}_{2} \mathrm{O}$, etc., se formariam moléculas mais complexas (aminoácidos, açúcares, ácidos nucléicos, lipídeos, etc.); depois de milhões de anos, tendo um grande acúmulo destas moléculas, elas se combinariam formando biopolímeros (peptídeos, polissacarídeos, nucleotídeos, etc.), que reagiriam entre si e formariam estruturas coacervadas (estruturas que parecem célula). Dentro destas estruturas e após milhões de anos, reações químicas começariam a ocorrer e seriam tão complexas que poderíamos considerar as estruturas coacervadas como vivas. ${ }^{1-3}$

\footnotetext{
*e-mail: damzaia@uel.br
}

Inicio da evolução dos seres vivos como proposto por Darwin

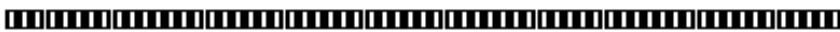

3,5 a 3,8 bilhões de anos atrás surgimento do primeiro ser vivo do planeta Terra

evolução das reações químicas dentro das estruturas coacervadas

síntese de estruturas coacervadas "células" (que podem ser constit uídas de lipídios, peptídeos, etc) a partir de biopolímeros (aminoácidos, açúcares, lipídios, etc)

síntese de biopolímeros (peptídeos, ) a partir de biomoléculas (aminoácidos, açúcares, lipídios, etc)

síntese de biomoléculas (aminoácidos, açúcares, lipídios, etc) a partir de moléculas simples $\left(\mathrm{CH}_{4}, \mathrm{CO}, \mathrm{CO}_{2}, \mathrm{H}_{2}, \mathrm{H}_{2} \mathrm{~S}, \mathrm{HCN}, \mathrm{NH}_{3}\right.$, $\mathrm{H}_{2} \mathrm{O}$, etc)

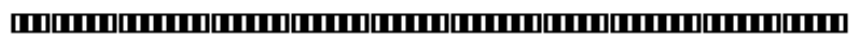

4,5 bilhões de anos atrás surgimento do planeta Terra

Figura 1. Esquema de Oparin-Haldane para o surgimento da vida

Em 1953, S. L. Miller, estudante de química que trabalhava no laboratório de Harold C. Urey (Prêmio Nobel de Química de 1934) na Universidade de Chicago, utilizando um equipamento, como mostrado na Figura 2, conseguiu sintetizar aminoácidos. Este equipamento simulava um ambiente que existiu na Terra primitiva: 


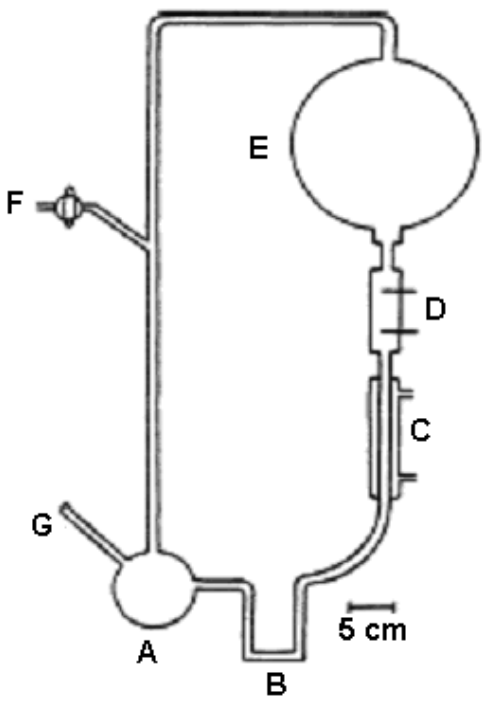

Figura 2. Aparelho utilizado por Miller para a síntese de aminoácidos: A frasco com água aquecido a $80{ }^{\circ} \mathrm{C} ; \mathrm{B}$ - tubo em U para evitar a circulação dos gases na direção oposta; $C$ - condensador; $D$ - eletrodos; $E$ - balão de $5 \mathrm{~L}$ onde foram adicionados os gases (metano, amônia e hidrogênio); $F$ - torneira ligada ao sistema de vácuo para fazer os gases circularem; $G$ - torneira para retirada de amostras

o frasco A, contendo água aquecida a $80{ }^{\circ} \mathrm{C}$, simularia o mar; o frasco E, preenchido com uma mistura de gases metano $\left(\mathrm{CH}_{4}\right)$, amônia $\left(\mathrm{NH}_{3}\right)$ e hidrogênio $\left(\mathrm{H}_{2}\right)$, simularia a atmosfera; os eletrodos $\mathrm{D}$ gerariam faíscas que simulariam os raios e também seriam fonte de energia para as reações químicas. A análise química da solução aquosa, algumas semanas depois do experimento iniciado, detectou a existência dos aminoácidos $\alpha$-alanina, $\beta$-alanina e $\alpha$-aminoácido-nbutírico. Este experimento confirmou a hipótese de Oparin-Haldane, ou seja, moléculas simples $\left(\mathrm{CH}_{4}, \mathrm{NH}_{3}, \mathrm{H}_{2}\right)$ reagiriam entre si em condições de reação que simulariam um ambiente da Terra primitiva e produziriam moléculas mais complexas. Miller, portanto, obteve os aminoácidos, que são blocos construtivos dos peptídeos e proteínas. Devemos salientar que a grande maioria das reações químicas que ocorrem nos seres vivos modernos, de alguma forma envolve aminoácidos e peptídeos e/ou proteínas. Com este experimento Miller iniciou o que chamamos de Química Prebiótica. Hoje sabemos que o experimento de Miller, do ponto de vista da química prebiótica, não é válido visto que a atmosfera da Terra primitiva nunca foi redutora $\left(\mathrm{CH}_{4}, \mathrm{NH}_{3}, \mathrm{H}_{2}\right)$, mas sim oxidante $\left(\mathrm{CO}_{2}, \mathrm{~N}_{2}, \mathrm{H}_{2}\right)$ e nesta atmosfera a quantidade de aminoácidos sintetizados é irrisória. Mesmo assim, este fato não tira a importância histórica do experimento de Miller, e existem centenas de outros experimentos que mostram que a hipótese de Oparin-Haldane é uma possibilidade. ${ }^{1-3}$

Em química prebiótica estudamos qualquer reação química em condições que simulem um ambiente que existiu ou que ainda exista na Terra e que possa ter contribuído para o surgimento de vida em nosso planeta. ${ }^{1,2}$

A discussão de como a vida surgiu em nosso planeta (se surgiu aqui!!!) pode ser feita por duas abordagens totalmente diferentes, uma delas chamada "de cima para baixo" (relacionada à biologia e à paleontologia) e a outra "de baixo para cima" (relacionada à química e à geologia). No primeiro caso começamos a avaliar a vida que conhecemos hoje e, a cada passo, a simplificamos, nesta visão, podemos perguntar: qual é o sistema mais simples que poderia ter evoluído para a vida como conhecemos hoje? Por exemplo, hemoglobina não era útil antes de termos em nossa atmosfera altas concentrações de oxigênio, então podemos retirar esta molécula do nosso modelo de célula. Esta forma de estudar o problema da origem da vida é campo para biólogos e paleontólogos que, utilizando-se deste modelo, estudam a paleontologia dos primeiros fósseis, biologia e química da origem e estabelecimento do mundo do DNA e do mundo do RNA, etc. No segundo caso, ou seja, "de baixo para cima", começamos com moléculas simples que se polimerizam e formam estruturas cada vez mais complexas; portanto, vamos do mais simples para o mais complexo até o surgimento do primeiro ser vivo. Esta forma de estudar o problema da origem da vida é campo para químicos e geólogos que estudam a origem de pequenas moléculas em condições de química prebiótica, a formação de ordem através da separação de fases e formação de membranas, a formação de polímeros a partir de aminoácidos, nucleotídeos, etc. e a formação do mundo do pré-RNA; com os conhecimendos de astrofísica, eles podem ainda avaliar o impacto, no surgimento da vida, das moléculas vindas do espaço que foram depositadas em nosso planeta por poeira estelar, meteoros ou cometas. ${ }^{1,4,5}$

Outra questão que devemos discutir é a complexidade dos primeiros organismos (não vivos) e dos seus ambientes. Temos neste caso quatro possibilidades: o primeiro organismo era simples e seu ambiente era complexo (origem heterotrófica); o primeiro organismo era simples e seu ambiente era simples (origem autotrófica); o primeiro organismo era complexo e seu ambiente era complexo (panspermia heterotrófica) e, o primeiro organismo era complexo e seu ambiente era simples (panspermia autotrófica). Os organismos heterotróficos necessitam de moléculas (proteínas, lipídeos, açúcares, etc.) previamente prontas para serem utilizadas como fonte de energia para outras sínteses; nós somos exemplos de organismos heterotróficos. Portanto, quando falamos de organismo simples e meio ambiente complexo e definimos isto como origem heterotrófica queremos dizer que este "organismo" precisou de um ambiente com moléculas complexas (açúcares, aminoácidos/peptídeos, etc.) como fonte de energia. Os organismos autotróficos são aqueles que sintetizam todas as suas biomoléculas a partir do dióxido carbono $\left(\mathrm{CO}_{2}\right)$ ou outra unidade de $\mathrm{C}_{1}$, como metano $\left(\mathrm{CH}_{4}\right)$, sendo as plantas exemplos de tais organismos. Assim, a relação organismo e meio ambiente simples (origem autotrófica) significa que o ambiente deste "organismo" foi constituído de moléculas simples $\left(\mathrm{CO}_{2}, \mathrm{CH}_{4}, \mathrm{H}_{2} \mathrm{~S}\right.$, etc) e a partir delas conseguiu sintetizar moléculas complexas. O primeiro organismo foi então heterotrófico ou autotrófico? Não sabemos a resposta a esta pergunta. A panspermia heterotrófica ou autotrófica não resolve o nosso problema de como a vida se originou, visto que nestes casos a vida foi originada em algum outro lugar e trazida ao nosso planeta de alguma forma (meteoro, cometa, etc.), portanto, simplesmente transferimos o problema para um outro planeta. ${ }^{1,4,5}$

\section{CONTROVÉRSIAS SOBRE A ORIGEM DA VIDA}

A Tabela 1 mostra as mais importantes controvérsias em relação à origem da vida em nosso planeta. No caso da origem heterotrófica estamos supondo um acúmulo de moléculas e polímeros complexos que possibilitaram a formação de estruturas complexas dentro de um esquema semelhante ao proposto por Oparin (1924) e Haldane (1929). Quanto à origem autotrófica, como proposto por Günter Wächtershäuser (1985), estamos supondo um ambiente pobre em biomoléculas, mas com um metabolismo complexo que possibilita compensar a falta de moléculas complexas. Como já discutimos anteriormente não temos condições hoje de saber qual dos dois modelos é o correto. No entanto, devemos salientar que com exceção dos modelos de metabolismo, proposto por Wächtershäuser, e código genético primitivo, proposto por Cairns-Smith, os quais vamos explicar abaixo, todos os 
Tabela 1. Controvérsias sobre a origem da vida

MODELO A versus MODELO B

Origem: heterotrófica (química prebiótica complexa e metabolismo simples)

Primeira etapa: genética (polímeros autoreplicantes)

Células: invenções posteriores (células são simples compartimentos para os sistemas replicadores)

Origem da vida: mineral (minerais foram importantes para origem da vida)

Origem: autotrófica (ambiente químico simples e metabolismo complexo)

Primeira etapa: metabolismo (mecanismos bioenergéticos primitivos)

Células: invenções iniciais (células são elementos necessários para bioenergética)

Origem da vida: não mineral (minerais não foram importantes para origem da vida)

outros modelos de origem da vida são heterotróficos, ou seja, todos os outros modelos de origem da vida (mundo do RNA, proteínas, lipídeos, poli-aromáticos, etc.) exigem um grande acúmulo de biomoléculas e biopolímeros complexos. ${ }^{4,6}$

A segunda controvérsia mostrada naTabela 1 refere-se a quem veio primeiro: o metabolismo ou a genética (polímeros autoreplicantes). Em 1988, Günter Wächtershäuser propôs um mecanismo de metabolismo autotrófico baseado na formação da pirita $\left(\mathrm{FeS}_{2}\right.$, chamado de ouro dos tolos devido sua coloração amarela). Os defensores do modelo proposto por Wächtershäuser acreditam que o metabolismo é uma invenção mais antiga que o código genético e o modelo não exige um ambiente complexo em termos de moléculas, ou seja, este modelo supõe uma origem autotrófica do primeiro ser vivo do nosso planeta. A fonte de energia para essas reações é fornecida pela reação química:

\section{$\mathrm{FeS}+\mathrm{H}_{2} \mathrm{~S}=\mathrm{FeS}_{2}$ (pirita) $+2 \mathrm{H}^{+}+2 \mathrm{e}^{-}$}

Os elétrons fornecidos pela formação da pirita podem ser utilizados para a redução de dióxido de carbono $\left(\mathrm{CO}_{2}\right)$, como mostrado na reação de formação do ácido succínico que é uma reação muito favorável, do ponto de vista termodinâmico, pois a energia livre de Gibbs é muito negativa $\left(\Delta \mathrm{G}^{\circ}=-420 \mathrm{~kJ} / \mathrm{mol}\right)$.

$$
4 \mathrm{CO}_{2}+7 \mathrm{FeS}+7 \mathrm{H}_{2} \mathrm{~S}=7 \mathrm{FeS}_{2}+4 \mathrm{H}_{2} \mathrm{O}+\left(\mathrm{CH}_{2} \mathrm{COOH}\right)_{2}
$$

Após a formação dos ácidos, os mesmos ficam adsorvidos ("grudados”) sobre a pirita formada, já que esta é carregada positivamente, então as moléculas podem sofrer novas reações aumentando sua complexidade, assim, temos aqui um modelo de um metabolismo de superfície (duas dimensões) autotrófico primitivo. ${ }^{6}$

A. G. Cairns-Smith (1975) propôs que o primeiro código genético deveria ser constituído de algum tipo de material simples e facilmente encontrado na natureza e que de alguma forma pudesse armazenar e transmitir informação. Quais substâncias poderiam desempenhar o papel de código genético primitivo? Segundo Cairns-Smith, argilas são ideais para tal fim visto que possuem as seguintes características: são abundantes na natureza, sempre existiram em nosso planeta, podem crescer (em soluções saturadas ocorre o crescimento de cristais) e dividir (podem quebrar) e são estruturas organizadas que podem reter e transmitir informações. Devemos salientar que neste modelo o código genético foi uma invenção mais antiga que o metabolismo. Ainda, segundo Cairns-Smith, um grupo de organismos (não vivos) primitivos G1 (argilas) desenvolve a capacidade de produzir diversos polímeros (alguns destes polímeros podem ser semelhantes ao RNA); este material produzido, o qual chamaremos de G2, em princípio não desempenha função nenhuma, ou seja, simplesmente contamina G1. Nesta simbiose, G1 fornece tecnologia (monômeros, catalisadores, condições para síntese, etc.) para que G2 se torne cada vez mais complexo e passe a inventar novas formas de fazer as coisas que G1 fazia. Obviamente, com o passar do tempo G2 fica tão sofisticado que não precisa mais de G1, este mecanismo Cairns-Smith chamou de takeover. O grande problema com a hipótese de Cairns-Smith é que até o momento não foi apresentada nenhuma prova experimental de que isto é possível. ${ }^{7}$

A descoberta, no início da década de 80 , de que moléculas de RNA também podem desempenhar o papel de catalisadores deu um novo interesse à comunidade científica para a possibilidade de que o código genético talvez tivesse sido a invenção mais antiga. Os defensores do mundo do RNA postulam que o código genético é uma invenção anterior ao metabolismo. O DNA é o responsável pela síntese de RNA que, por sua vez, é o responsável pela síntese de proteínas e algumas enzimas catalisam a síntese de DNA e RNA. Este fluxo de informação de DNA para RNA e para proteínas é chamado de dogma central da biologia molecular. A primeira pergunta que podemos fazer é: quem surgiu primeiro foi o DNA, o RNA ou as proteínas? O DNA é uma molécula bastante complexa em estrutura, tendo uma baixa probabilidade de ter sido o primeiro a surgir de maneira abiótica. Além disso, o DNA não é capaz de fazer cópias dele mesmo sozinho, precisando da ajuda de RNAs e de proteínas para que a informação nele contida se expresse e seja preservada nas moléculas-filhas. Isto torna mais improvável ainda a sua participação inicial na origem da vida. Embora as proteínas se mostrem extremamente versáteis, existe uma grande tendência na comunidade científica em aceitar que o RNA é o mais primordial dos três polímeros. Isto decorre do fato de que RNA pode armazenar informações e catalisar reações. Entretanto, diversas objeções têm sido colocadas em relação ao mundo do RNA sendo estas: o fosfato encontrado na Terra está na forma insolúvel, então não está disponível para síntese dos nucleotídeos; as moléculas de nucleotídeos são muito complexas e provavelmente foram produzidas em pequenas quantidades não possibilitando a formação de polímeros e, as impurezas (mistura de muitas moléculas diferentes) existentes na Terra primitiva não possibilitariam as reações do mundo dos RNAs. Atualmente, é consenso na comunidade científica que o mundo dos RNAs não poderia ter ocorrido em condições de química prebiótica, mas sim foi uma invenção posterior, quando um certo grau de complexidade já havia sido atingido pelos primeiros organismos (não vivos). No entanto, os defensores de uma ou de outra possibilidade têm debatido muito, não chegando a algum consenso. ${ }^{4-8}$

Quanto à terceira controvérsia mostrada na Tabela 1 , muitos que defendem as células como invenções iniciais, argumentam que é muito difícil imaginar o surgimento de uma maquinaria complexa que não esteja separada de seu meio ambiente. A membrana de uma célula serve como uma barreira de permeabilidade que permite à célula manter a composição interna diferente da composição do líquido extracelular. A membrana celular dos seres vivos modernos, isto é, dos animais, é uma estrutura deformável e elástica cuja espessura pode variar de 7,5-10,0 nm. A composição química dessas membranas celulares é em média $55 \%$ de proteínas, $25 \%$ de fosfolipídeos, $13 \%$ de colesterol, $3 \%$ de outros lipídeos e $3 \%$ de carboidratos. Devemos salientar que alguns pesquisadores consideram que membranas foram importantes para criação de microambientes dentro dos quais a evolução molecular ocorreu. Segundo estes pesquisadores, as membranas foram invenções que ocorreram logo no início da evolução molecular. As membranas estudadas em química prebiótica podem ser inorgânicas ou orgânicas. As membranas inorgânicas podem ser constituídas de sais $\left(\mathrm{CaCl}_{2}, \mathrm{CoCl}_{3}, \mathrm{Na}_{2} \mathrm{SiO}_{3}\right.$, et. $)$, argilas ou zeolitas. As membranas orgânicas podem ser constituídas de aminoácidos, lipídios, etc. Contudo, baseados no estudo da composição do material orgânico 
encontrado no meteoro Murchison, alguns pesquisadores propõem que as primeiras membranas foram constituídas de uma mistura de ácidos monocarboxílicos e aromáticos policíclicos. ${ }^{9}$

A última controvérsia citada na Tabela 1 refere-se ao papel desempenhado pelos minerais na origem da vida. É natural imaginar que os minerais desempenharam algum papel na origem da vida, visto que sempre estiveram presentes, porém, é muito difícil dizer até que ponto foram realmente importantes. Os defensores desta idéia argumentam que os minerais, além de terem agido como concentradores de biomoléculas e polímeros e como catalisadores de reações químicas, podem ter desempenhado um importante papel como: código genético primitivo (modelo de A. G. Cairns-Smith), parede celular e metabolismo (modelo de Günter Wächtershäuser). Minerais obviamente desempenharam algum tipo de papel na origem da vida em nosso planeta,porém, alguns pesquisadores discordam que os mesmos tenham sido tão importantes. . $^{6,7,9,10}$

Obviamente estas controvérsias não serão resolvidas facilmente, pois muitas delas envolvem questões complexas, no entanto, servem para mostrar o grau de dificuldade envolvido na questão da origem da vida.

\section{REFERÊNCIAS}

1. Zaia, D.A.M.; Quim. Nova 2003, 26, 260; Zaia, D.A.M.; Semina 2004, 25, 3; Bruschi, L.C.A.; A Origem da Vida e o Destino da Matéria, Universidade Estadual de Londrina: Londrina, 1999; de Duve, C.; Poeira Vital, Campos: Rio de Janeiro, 1997; Reeves, H.; de Rosnay,
J. Coppens, Y; Simonnet, D.; A mais bela história do mundo, Vozes: Petrópolis, 1998; Damineli, A.; Damineli, D.S.C.; Estudos Avançados 2007, 59, 263.

2. Penny, D.; Biol. Philos. 2005, 20, 633.

3. Miller, S. L.; Science 1953, 117, 528.

4. Peretó, J.; Int. Microbiol. 200, 58, 23.

5. Luisi, P. L.; Orig. Life Evolut. Biosph. 1998, 28, 613.

6. Wächtershäuser, G.; Microbiol. Rev. 1988, 52, 452.

7. Cairns-Smith, A. G.; Seven clues to the origin of life, Cambridge University Press: UK, 1985; Cairns-Smith, A. G.; Genetic takeover and the mineral origin of life, Cambridge University Press, UK, 1982.

8. Orgel, L. E.; Orig. Life Evol. Biosph. 2003, 33, 211.

9. Deamer, D.; Dworkin, J. P.; Sandford, S. A.; Bernstein, M. P.; Allamandola, J.; Astrobiology 2002, 2, 371; Segré, D.; Ben-Eli, D.; Deamer, D. W.; Lancet, D.; Orig. Life Evol. Biosph. 2001, 31, 119; Snyder, W. D.; Fox, S. W.; BioSystems 1975, 7, 222; Zaia, D.A.M. Em Entendendo a gordura: os ácidos graxos; Curi, R.; Pompéia, C.; Miyasaka, C. K.; Procópio, J., eds.; Manole: Barueri, 2002, cap. 1.

10. Zaia, D. A. M.; Zaia, C. T. B. V.; Ciência Hoje 2005, 37, 38; Zaia, D. A. M.; Vieira, H. J.; Zaia, C. T. B. V.; J. Braz. Chem. Soc. 2002, 13, 679; Zaia, D.A.M.; Amino Acids 2004, 27, 113; Zaia, D.A.M.; Zaia, C. T. B. V.; Quím. Nova 2006, 29, 786; Benetoli, L. O. B.; de Souza, C. M. D.; da Silva, K. L.; de Souza Jr., I. G.; de Santana, H.; Paesano Jr., A.; da Costa, A. C. S.; Zaia, C. T. B. V.; Zaia, D. A. M.; Orig. Life Evol. Biosph. 2007, 37, 479; Lahav, N.; Heterogeneous Chem. Rev. 1994, 1, 159; Benetoli, L. O. B.; de Santana, H.; Zaia, C. T. B. V.; Zaia, D. A. M.; Monatsh. Chem. 2008, 139, 753. 